\title{
Marcas Históricas da Identidade do Professor que Ensina Matemática: mulheres em destaque nos Boletins do CPOE
}

Maria Cecilia Bueno Fischer*, Diogo Franco Rios**

\section{Resumo}

Buscando oferecer uma contribuição à construção histórica da identidade do professor que ensina Matemática, apresentamos um exercício de identificação de personagens que atuaram junto ao Centro de Pesquisas e Orientação Educacionais (CPOE), órgão da Secretaria de Educação e Cultura do Rio Grande do Sul, na tentativa de melhor compreender seu funcionamento na gestão da Educação Primária e, por decorrência, da Escola Normal no estado. Para tal, foram tomadas como fontes as publicações contidas nos Boletins do Centro, datados de 1947 a 1966 , relacionadas ao ensino de Matemática, sendo considerados como representativos dos discursos oficiais do CPOE nesse período. Como resultado destaca-se que coube apenas a mulheres, professoras e técnicas em educação, a autoria das produções contendo reflexões, orientações e diretrizes relacionadas à Matemática e, em função do lugar que ocupavam no Centro, acabaram por assumir a função de experts, uma vez que suas produções eram reconhecidas como legítimas proposições do Centro para os professores do estado.

Palavras-chave: Ensino Primário; Escola Normal; Centro de Pesquisas e Orientação Educacionais; Matemática; Mulheres.

\footnotetext{
* Docente da Universidade Federal do Rio Grande do Sul - UFRGS. Brasil. E-mail: mceciliabfischer@gmail.com

** Docente da Universidade Federal de Pelotas - UFPel. Brasil. E-mail: riosdf@hotmail.com
} 


\section{Introdução}

Ao sermos provocados a tratar sobre a construção histórica da identidade do professor de Matemática, voltamo-nos a uma discussão que vimos fazendo sobre o papel de destaque que algumas personagens assumiram no estado do Rio Grande do Sul nos anos 1950 a 1970, identificando a atuação delas junto ao Centro de Pesquisas e Orientação Educacionais (CPOE) como uma contribuição à formação da identidade do professor que ensina Matemática, no nosso caso, professoras que produziram reflexões, orientações e diretrizes para a disciplina no Ensino Primário e na Escola Normal, nos anos de existência do CPOE.

Estamos considerando que a identidade docente é construída historicamente e, por isso, aspectos regionais e temporais são fortes tensionadores que precisam ser pensados, o que justifica o esforço por compreender os mecanismos que interferiram no fazer docente, os saberes envolvidos e os processos de recepção e apropriação de modelos educativos que se fizeram circular naquela época no Rio Grande do Sul. Tomaremos aqui o entendimento da identidade docente, assim como explica Pimenta:

Uma identidade profissional se constrói, pois, a partir da significação social da profissão; da revisão constante dos significados sociais da profissão; da revisão das tradições. Mas também da reafirmação de práticas consagradas culturalmente e que permanecem significativas. Práticas que resistem a inovações porque prenhes de saberes válidos às necessidades da realidade. Do confronto entre as teorias e as práticas, da análise sistemática das práticas à luz das teorias existentes, da construção de novas teorias. Constrói-se, também, pelo significado que cada professor, enquanto ator e autor, confere à atividade docente no seu cotidiano a partir de seus valores, de seu modo de situar-se no mundo, de sua história de vida, de suas representações, de seus saberes, de suas angústias e anseios, do sentido que tem em sua vida o ser professor (PIMENTA, 1999, p. 19).

A partir desse entendimento, reconhecemos que a construção histórica da identidade docente é uma questão bastante complexa e cuja discussão que aqui trazemos não esgota o debate. Como afirmado, apresentamos a atuação de educadoras do CPOE que contribuíram com produções relativas à Matemática voltadas a professores primários gaúchos e, por associação, à formação dessas profissionais nos Cursos Normais, em grande medida.

Há algum tempo tem sido produzidas reflexões sobre o $\mathrm{CPOE}^{1}$ e seu papel na educação primária gaúcha. No âmbito da Matemática, alguns trabalhos têm sido produzidos no sentido de identificar orientações relacionadas à disciplina escolar reconhecendo, inclusive, uma importante relação que existiu entre o Centro e a 
Revista do Ensino do Rio Grande do Sul (RE/RS), periódico da Secretaria de Educação e Cultura do Estado (SEC/RS), tanto que parte do era publicado nos Boletins também saia publicado na Revista. A Revista do Ensino do Rio Grande do Sul foi criada em 1951 e passa a se constituir, em 1956, como uma publicação oficial do estado, sob a supervisão do Centro (FISCHER, 2010).

Dos trabalhos mencionados, surge-nos uma questão ainda pouco investigada e que pretendemos, neste artigo, trazer algumas considerações a respeito: quem foram as pessoas envolvidas na produção de orientações e prescrições relativas à Matemática produzidas pelo CPOE?

Neste trabalho não estamos defendendo especificamente a produção de biografias ou histórias de vida das personagens ligados às propostas e orientações relativas à Matemática feitas no âmbito do CPOE. Nosso objetivo é apresentar aqui um primeiro esforço para responder a questão colocada, por reconhecermos que compreender o papel e as ações do CPOE na gestão da educação primária gaúcha passa por avançarmos no entendimento sobre os personagens envolvidos com esses processos, escolhidos e autorizados pelo Centro para falarem em seu nome nas proposições, orientações para a educação primária no estado, enquanto tal função lhe foi formalmente atribuída.

A construção da questão que ora trazemos se deu no desenvolvimento do projeto de pesquisa ${ }^{2}$ em que estamos envolvidos, seguindo algumas análises que apontaram para o CPOE como um Centro que agregava uma série de personagens envolvidos nas dinâmicas de orientação, formação de professores do Ensino Primário gaúcho e, por decorrência, também do Ensino Normal no estado do Rio Grande do Sul, entre os anos de 1943 e 1971, enquanto esteve em funcionamento (FISCHER; FISCHER, 2015).

$\mathrm{O}$ interesse por essa questão de investigação mais específica faz parte de um novo projeto de pesquisa interinstitucional, em fase de composição, e que pretende, entre outras demandas, aprofundar a compreensão historiográfica a respeito da formação matemática voltada para o Curso Primário e para o Curso Normal no estado, tendo como premissa que o CPOE foi um órgão centralizador e propositor de orientações pedagógicas para esses níveis de ensino, que fez a gestão inclusive dos livros didáticos que os professores deveriam escolher (RIOS; FISCHER, 2018) e que aglutinou personagens com "função de experts" para orientar, propor, definir e avaliar o ensino de Matemática, especialmente para o Ensino Primário.

Tratamos aqui o conceito de expert no sentido que Valente, Almeida e Silva (2020) apresentam: "o expert em educação refere-se a um personagem ou grupo de 
pessoas que recebem atribuições das autoridades de ensino de modo a assessorá-las, com a produção de saberes que embasem uma decisão oficial, na resolução de um problema prático" (p. 67). Assim, nossas personagens assumem a função de experts ao assessorarem o CPOE na orientação aos professores gaúchos, a partir das publicações nos Boletins do Centro.

Quadros (2006) ao procurar mostrar as "condições de emergência, de inserção e de funcionamento" (p. 14) do CPOE, destaca a relevância do Centro no sistema educacional gaúcho, referindo que "seus enunciados, e não outros, definiam a verdade que podia ser pensada e quem podia ocupar o lugar de sujeito para pronunciá-la" (p. 284). Nesse sentido, é que se situa nossa investigação pelas personagens que puderam ocupar a função de experts, e que deveriam estar afinadas com o discurso do Centro e “autorizadas" a pronunciá-lo.

Já foi possível explicar que o CPOE, órgão vinculado à SEC/RS, desempenhou um papel fundamental na gestão da educação primária. Suas atividades de orientação técnico-pedagógica para a rede escolar do RS iniciaram em 1943, em plena reforma educacional empreendida à época, com "atuação marcante no controle organizacional do sistema educativo gaúcho até 1971, ano em que foi extinto" (RIOS; FISCHER, 2018, p. 55).

Atuando como um centro gestor da educação primária, tinha, por decorrência, ingerência sobre a formação nas Escolas Normais. Para a finalidade deste texto, não pretendemos separar o Ensino Primário da formação de normalistas, mas considerar a relação entre esses níveis de ensino e a responsabilidade do CPOE nas determinações e orientações destinadas a ambos.

Do mesmo modo, sem pretender discutir mais aprofundadamente sobre os diferentes graus de ingerência do CPOE nesses níveis de ensino, estamos tomando como premissa que o Ensino Primário e o Curso Normal não estiveram, em absoluto, separados, mas se inter-relacionavam em função das finalidades educativas que lhes eram atribuídas: a formação escolar para o Ensino Primário e a formação de normalistas para atuarem naquele nível escolar.

Considerando que estamos tomando o CPOE como um centro responsável, em nome do Estado, por gerir o Ensino Primário e o Ensino Normal, em certa medida, e que teve um importante papel na definição de políticas públicas, de modo geral, para esses dois níveis educacionais, nos parece muito apropriado o exercício analítico de identificar os personagens ligados à Matemática do Ensino Primário e do Curso 
Normal, vinculados a diferentes setores do CPOE, por terem ocupado esse lugar autorizado a falar em nome do Centro, sendo-lhes atribuída a função de experts.

No caso de nosso levantamento de personagens que atuaram com Matemática no CPOE, como já sinalizado, só identificamos mulheres. O papel feminino, seja em pesquisa historiográficas relativas ao Ensino Secundário, seja em relação ao Ensino Primário ou ao Curso Normal já vem sendo reconhecido pelas pesquisas próprias da História da Educação Matemática (VALENTE, 2013), quanto em pesquisas em História da Educação, que reconhecem a feminização do magistério primário brasileiro e, em decorrência, a presença massiva delas nas Escolas Normais, são exemplos dessas produções Tambara (1998), Werle, (2005) e Fraga (2017).

Em relação às personagens que nos interessa identificar, buscamos reconhecer atividades ou produções que nos permitam caracterizá-las como detentoras de uma expertise, isto é, de "uma instância, em princípio reconhecida como legítima, atribuída a um ou a vários especialistas - supostamente distinguidos pelos seus conhecimentos, atitudes, experiências -, a fim de examinar uma situação, de avaliar um fenômeno, de constatar fatos" (HOFSTTETER; SCHNEUWLY; FREYMOND, 2017 , p. 57). Estes autores embasam o significado de expert que assumimos neste texto, elaborado por Valente, Almeida e Souza (2020), referido antes. Discutimos, por outro lado, que o lugar de destaque ocupado por esses personagens diz respeito às condições de reconhecimento dessa distinção, não necessariamente associado a uma competência diferenciada para tal exercício, mas especialmente em função da autorização para falar "em nome de" ou o lugar de autoridade, que lhes fora atribuída pelo CPOE, gestor da educação primária no Rio Grande do Sul naqueles anos.

Nesse sentido é que destacamos algumas personagens que atuaram no CPOE, considerando que suas publicações nos Boletins, imbuídas de autoridade para tanto, eram reconhecidas como legítimas orientações do Centro para os professores do estado. Estamos nos referindo, neste texto, às publicações envolvendo a Matemática, dirigidas ao Ensino Primário e à Escola Normal.

Até o momento, não identificamos investigações ${ }^{3}$ que tenham priorizado a performance dessas personagens ligadas ao CPOE e que discutam como aquelas ligadas à Matemática passaram a compor a equipe, que identifiquem as ações que desempenharam em cada setor, como as desenvolveram, como interagiram com discursos pedagógicos da época para orientar suas ações, como se apropriaram dos 
discursos pedagógicos que circulavam na composição das propostas que fizeram e como se lembram da atuação que realizaram.

Com a intenção de apresentarmos os primeiros resultados relativos a um estudo voltado às personagens que atuaram no $\mathrm{CPOE}$, no âmbito da Matemática, tomamos como fonte de pesquisa os Boletins do CPOE, fato que restringe a abrangência temporal quanto à discussão sobre a gestão do Centro, que seguiu em funcionamento até 1971, na formação matemática dos dois níveis de ensino considerados.

Nos treze Boletins ${ }^{4}$, publicados entre 1947 e 1966, o conteúdo inclui

[...] desde decretos e demais documentos de base legal advindos da SEC/RS, como comunicados do CPOE, informações sobre missões pedagógicas, sobre cursos de formação de professores (para a Escola Normal e também para professores em serviço), além de inúmeras sugestões de temas e atividades didáticas para as disciplinas do currículo do ensino primário, com especial ênfase para leitura e escrita, seguida da matemática. Também há convocações de gestores para reuniões e cursos, relatórios parciais e finais de ano letivo, dados estatísticos e demais informes sobre programas ou reformas efetivadas. Não raro é se encontrar assuntos específicos sobre livros e filmes recomendados às escolas e professores (FISCHER; FISCHER, 2015, p. 78-79).

Os Boletins nos pareceram fontes de pesquisa interessante para iniciarmos nossa investigação, uma vez que podem ser tomados como representativos dos discursos oficiais do CPOE. Eram produzidos aglutinando o conjunto de publicações oficiais da Instituição no ano ou nos anos anteriores e que já haviam sido divulgadas, em sua grande maioria, por correspondência para as instituições escolares ou publicadas em diferentes números da RE/RS, sendo boa parte delas assinadas pelos elaboradores, pelos setores do CPOE ou, ainda, pela direção do Centro.

\section{Identificando personagens}

Como estratégia inicial de identificação das personagens, fizemos um exercício de entrecruzamento das menções de personagens ligados ao CPOE e às produções/ orientações relacionadas à Matemática nos doze Boletins que já haviam sido objeto de análise de Fischer e Fischer (2015), em que foram identificadas publicações voltadas à disciplina, com destaque "a três abordagens: a) a que trata da gestão de processos avaliativos e orientações para a elaboração de provas; b) a que apresenta sugestões para o ensino de Matemática; e c) a que contempla a aplicação da Matemática em atividades da Escola" (p. 81).

A estrutura organizacional do CPOE foi sendo alterada ao longo dos anos (QUADROS, 2006), contudo tais modificações não pareceram alterar profundamente 
a estruturação inicial. Na primeira estrutura do Centro divulgada nos Boletins, identifica-se a "secção de orientação", subdividida em "pré-primário", "primário fundamental", "supletivo" e "normal"; a "secção de provas", subdividida apenas em "primário" e "normal" e a "secção de pesquisa" subdividida em "pré-primário", "primário", "secundário" e "normal". Além dessas secções, o CPOE possuía ainda os "serviços técnicos auxiliares", "serviços administrativos auxiliares" e "biblioteca" (RIO GRANDE DO SUL, 1947, p. 11). No final dos anos 1950 e início dos anos 1960, são apresentados outros detalhamentos da estrutura do CPOE, com algumas variações de nomes, sendo divulgado no Boletim de 1965-1966 o regimento do Centro com uma estrutura detalhada, na qual se explica a função de cada setor e as responsabilidades assumidas, sendo subdividido em: "Divisão de Pesquisas", "Divisão de Orientação", "Divisão de Telecomunicação Educativa" e "Biblioteca Especializada". Particularmente, chama a atenção constar, como uma divisão específica na estrutura do CPOE, a "Revista do Ensino" (RIO GRANDE DO SUL, 1965-1966, p. 255-256).

A identificação dos profissionais do Centro, indicando os diversos setores em que atuavam, era bastante frequente nos Boletins e, em vários deles, há listas ${ }^{5} \mathrm{em}$ que constam os perfis desses profissionais, de onde se pode inferir a organização do trabalho no CPOE. Para além da divisão em secções, a estrutura do Centro também estava definida em função do perfil de profissionais a ele ligados: técnicos em educação, professores à disposição, psicólogos, orientadores educacionais (diversos níveis), além dos cargos de direção e daqueles associados às coordenações das secções.

Do levantamento que fizemos dos diferentes documentos publicados nos Boletins, apresentamos, na tabela a seguir, um primeiro rastreamento de autoras cujas produções, de algum modo, remetem ao ensino de Matemática, fosse em relação ao conteúdo ou à prática de ensino dos professores.

Antes, é preciso referir que alguns documentos publicados nos Boletins não apresentam autoria clara, apenas sendo assinados pela direção ou pela coordenadora da secção propositora. Desse modo, além da identificação de personagens que já nos foi possível apresentar, todas mulheres, outros ainda poderão ser identificados. Contudo, essa identificação demanda a localização de outros documentos ou a realização de entrevistas com personagens que lá atuaram. No momento, estamos buscando informações que nos indiquem a localização de vestígios relativos ao CPOE, para podermos avançar nas explicações pretendidas. 
Tabela 1 - Associação entre personagens do CPOE e publicações associadas à Matemática nos Boletins do Centro

(continua)

\begin{tabular}{|c|c|c|}
\hline Personagem & Identificação & $\begin{array}{l}\text { Ano do Boletim/Publicação } \\
\text { associada à Matemática }\end{array}$ \\
\hline $\begin{array}{l}\text { Sarah } \\
\text { Azambuja } \\
\text { Rolla }\end{array}$ & $\begin{array}{l}\text { Técnica em Educação, } \\
\text { assume a direção do } \\
\text { CPOE em fevereiro de } \\
\text { 1959, após a saída de } \\
\text { Alda C. Kremer, e perma- } \\
\text { nece no cargo até o final } \\
\text { de } 1962 \text {. }\end{array}$ & $\begin{array}{l}\text { - } 1954-55, \text { p. 123-135 - Sugestões para o ensino da Matemática nas classes de } 1^{\circ} \text { ano, assinado } \\
\text { por: Sara Rolla; Eloah B. Ribeiro; Margarida Sirângelo; Noely Sagebin; Maria Fernandes Oliveira. } \\
\text { Uma versão revisada foi publicada no Boletim 1956-57, p. 88-97; } \\
\text { - } 1959, \text { p. } 70-73 \text { - assina Comunicado sobre "Classes de Recuperação"; } \\
\text { - } 1959, \text { p. } 73-82 \text { - assina Comunicado aos diretores sobre organização de provas para as classes } \\
\text { especiais; } \\
\text { - } 1959 \text {, p. } 170-171 \text { - assina Ofício-circular aos delegados sobre instruções referentes às revisões } \\
\text { mensais e às provas orais; } \\
\text { - } 1960 \text {, p. } 11-35 \text { - assina ofício-circular aos Diretores, sobre divulgação às professoras dos Subsí- } \\
\text { dios no 1, de orientação pré-primária. Produção de autoria de Gladys Hadda Corrêa Vieira (Encar- } \\
\text { regada do Setor de Educ. Pré-Primária); } \\
\text { - } 1961-62, \text { p. } 116 \text { - assina Ofício circular aos diretores, divulgando sugestões de atividades para ho- } \\
\text { menagens a Landell de Moura (Ano Landelliano). Sugestões de Matemática nas páginas 120-123; } \\
\text { - } 1961-62, \text { p. } 472-473 \text { - supervisora geral da elaboração das "Diretrizes gerais para elaboração e } \\
\text { aplicação de provas de admissão aos Cursos Normais de } 1^{\circ} \text { e } 2^{\circ} \text { ciclos". }\end{array}$ \\
\hline
\end{tabular}


(conclusão)

\begin{tabular}{|c|c|c|}
\hline $\begin{array}{l}\text { Glacira } \\
\text { Amaral } \\
\text { Barros }\end{array}$ & $\begin{array}{l}\text { Professora à disposição } \\
\text { do CPOE tendo sido } \\
\text { identificada como Coor- } \\
\text { denadora da Secção de } \\
\text { Ensino Normal e Secun- } \\
\text { dário em } 1962 \text {. }\end{array}$ & $\begin{array}{l}\text { - 1961-62, p. 472-473 - integra o grupo que produziu as "Diretrizes gerais para elaboração e aplica- } \\
\text { ção de provas de admissão aos Cursos Normais de } 1^{\circ} \text { e } 2^{\circ} \text { ciclos"; } \\
\text { - 1963-64, p. 111-115 - está indicada, junto com Celestina Rosa e Silva, como tendo colaborado na } \\
\text { elaboração das Diretrizes básicas para Direção da Aprendizagem em Matemática. }\end{array}$ \\
\hline $\begin{array}{l}\text { Celestina } \\
\text { Rosa e Silva }\end{array}$ & $\begin{array}{l}\text { Professora à disposição } \\
\text { do CPOE }\end{array}$ & $\begin{array}{l}\text { - 1961-62, p. 472-473 - integra o grupo de professoras que produziram as "Diretrizes gerais para } \\
\text { elaboração e aplicação de provas de admissão aos Cursos Normais de } 1^{\circ} \text { e } 2^{\circ} \text { ciclos"; } \\
\text { - 1963-64, p. 111-115 - está indicada, junto com Glacira Amaral Barros, como tendo colaborado na } \\
\text { elaboração das Diretrizes básicas para Direção da Aprendizagem em Matemática; } \\
\text { - } 1963-64, \text { p. 165-166 - elabora bibliografia da Direção da Aprendizagem em Matemática, em "Re- } \\
\text { lações Bibliográficas". }\end{array}$ \\
\hline $\begin{array}{l}\text { Odete } \\
\text { Campos }\end{array}$ & $\begin{array}{l}\text { Técnica em Educação, } \\
\text { tendo atuado como Co- } \\
\text { ordenadora da Secção } \\
\text { do Ensino Primário em } \\
1959\end{array}$ & $\begin{array}{l}\text { - 1961-62, p. 159-167 - Elabora o Comunicado n 7: "Fatos fundamentais das operações de núme- } \\
\text { ros inteiros - Técnica de apresentação - Fixação da aprendizagem - Verificação"; } \\
\text { - } 1961-62, \text { p. 168-178 - dando sequência ao comunicado nº 7, organiza "Sugestões práticas", con- } \\
\text { tendo uma abordagem diferente por propor construção de material e atividades de "fixação da } \\
\text { aprendizagem", seguida de referências específicas; } \\
\text { - 1961-62, p. 182-187 - Elabora o Comunicado no } 10 \text { A: Esclarecimentos sobre a "Conversão de } \\
\text { Frações ao Mesmo Denominador", conteúdo presente no Programa Experimental de 1959; } \\
\text { - } 1961-62, \text { p. } 216 \text { - organiza a "Bibliografia para a Didática da Matemática". }\end{array}$ \\
\hline
\end{tabular}


A tabela 1 apresenta uma síntese das publicações assinadas nos Boletins, referentes à Matemática, sobre as quais apresentamos algumas considerações que apontam para o trabalho de suas autoras, dando um panorama da contribuição delas nesse campo, conforme detalhamos um pouco mais a seguir.

Eloah Brodt Ribeiro participou da criação do Boletim do CPOE (FRAGA, 2017, p. 66). Assina a publicação "Considerações em torno do processo de medida adotado em Matemática para seleção dos candidatos à escola de professores”, em 1947, período em que foi diretora do CPOE. Refere-se a uma análise do conteúdo matemático adotado no exame de admissão realizado em fevereiro de 1947, em que participaram 402 candidatos. sendo adotado um programa com "base cultural necessária à formação da personalidade do professor primário" (RIBEIRO, 1947, p. 13). O processo seletivo foi realizado conforme previsto na Lei Orgânica do Ensino Normal, com abrangência federal (BRASIL, 1946).

Destacam-se saberes voltados ao ensino de Matemática na referência às capacidades desejadas dos alunos como: sensibilidade de intuir, deduzir, transferir, organização lógica e reversibilidade de pensamento. Evidencia-se no texto o desejo que no processo de avaliação da Matemática seja superada a verificação de habilidades mecânicas, privilegiando-se a capacidade de raciocínio. Ao mesmo tempo, há o reconhecimento de que "em nossas escolas o aspecto mecânico da Matemática se sobrepõe ao racional" estando longe da "perfeição desejada" e, por isso, as questões da prova privilegiam tal aspecto RIBEIRO, 1947, p. 29). Fraga (2017) registra que Eloah recebeu o título de Educadora Emérita concedido pelo governo do estado do RS, sem indicar a data da concessão.

Como diretora do CPOE em dois períodos, Alda Cardoso Kremer assinou dois ofícios circulares: no de 1958, o ofício encaminha orientações aos diretores de escola quanto às comemorações do dia pan-americano, destacando a importância de todas as escolas darem o devido valor a tal comemoração, como "oportunidade de levar o educando a formar hábitos e atitudes de fraternidade, sadia compreensão da realidade americana, sentimentos generosos de serviço, de cooperação e solidariedade continental" (KREMER, 1958, p. 27), em que estavam incluídas "oportunidades de aprendizagem" de Linguagem, Matemática e Conhecimentos Gerais.

O outro ofício, de 1964, encaminha instruções gerais, com sugestões para a elaboração, na escola, das provas finais de Linguagem, Matemática, Estudos Sociais e Ciências Naturais. Percebe-se, no documento, uma orientação que assegure um caráter 
científico para o processo de avaliação do rendimento da aprendizagem dos alunos por meio das provas. Nas instruções específicas para a prova de Matemática, indica-se que a prova poderá contemplar "cálculos em geral, resolução de problemas, conhecimentos de significações, de relações, de natureza e de estrutura de fatos matemáticos em geral, aptidão para ler gráficos, cartas, etc" (KREMER, 1964, p. 287). Ao final do documento, destaca-se o peso da prova final, 60\%, para a classificação final dos alunos, sendo os $40 \%$ obtidos pela média das revisões mensais, as quais deverão utilizar dinâmicas e recursos variados. Neste segundo ofício observa-se uma das marcas das publicações do CPOE, voltadas aos processos avaliativos (FISCHER; FISCHER, 2015), com orientações, para a elaboração das provas, naquele ano, na própria escola, diferente de outros anos, em que o CPOE encaminhava o que ficou conhecido como "provas prontas", como narrado nas memórias de uma ex-normalista (RIOS; FISCHER, 2019).

Sarah de Azambuja Rolla atuou como assistente de Direção do CPOE, tendo assumido a direção do Centro entre 1959 e 1963. Nesse período assina alguns documentos com orientações aos professores, como é o caso dos ofícios elencados na tabela. São comunicados visando integrar os educadores riograndenses no "espírito da experiência" com a Reforma do Ensino Primário, ao tratar das classes de recuperação e da organização de provas para as classes especiais. Observa-se aqui, novamente, uma publicação voltada a processos avaliativos, tema recorrente nas publicações do Centro.

A técnica assina também um ofício aos diretores, recomendando a divulgação de subsídios de orientação pré-primária às professoras "jardineiras", isto é, que atuavam em Jardins de Infância, como eram denominadas as turmas de educação pré-escolar. Além disso, ainda como diretora, supervisiona a elaboração das "Diretrizes gerais para elaboração e aplicação de provas de admissão aos Cursos Normais de $1^{\circ}$ e $2^{\circ}$ ciclos". Segundo Fraga (2017), Sarah é também autora de vários artigos na Revista do Ensino/RS em que a maioria trata de "assuntos da aprendizagem na escola primária, principalmente questões ligadas à linguagem e à matemática” (p. 121) e, também, de livros didáticos.

Sara A. Rolla ainda assina, juntamente com Eloah B. Ribeiro, Margarida de Souza Sirângelo, Noely Sagebin e Maria Fernandes Oliveira, o texto "Sugestões para o ensino da Matemática nas classes de 1ํano" que, pelo registro, sugere ter sido escrito em dezembro de 1954. As últimas três figuram, como coautoras, apenas neste texto relativo à Matemática. Uma versão revisada também foi publicada no Boletim 1956-57, como parte do Comunicado no 5 (ROLLA et al., 1954-1955, p. $123-135 ; 1956-1957$, p. 88-97). 
No texto nota-se a influência da psicologia da educação, associando o concreto com mecanismos estimuladores da aprendizagem abstrata. Além de sugestões quanto a adaptar-se aos novos modelos sociais, há uma sinalização do papel propedêutico da Matemática no Ensino Primário. Como se trata de "sugestões para as classes de $1^{\circ}$ ano", pode-se afirmar a presença de discursos modernizadores, que nos anos seguintes se farão muito presentes em publicações associadas ao CPOE (RIOS; FISCHER, 2016), ainda que nesse caso não se possa fazer uma associação com a Matemática Moderna.

O texto não explicita suas referências, o que não possibilita concluir como as autoras tiveram contato com essas propostas, demonstrando a importância de um avanço na direção de compreender as condições de possibilidade de defenderem àquela altura tais perspectivas.

Glacira Amaral Barros integra o grupo de professoras que produziram "as diretrizes para a elaboração e aplicação das provas de admissão aos Cursos Normais de $1^{\circ}$ e $2^{\circ}$ ciclos", além das "instruções especiais para as provas de Língua Portuguesa, Matemática e Conhecimentos Gerais" que figuram na sequência. Curiosamente, apesar de prometidas, não constam as diretrizes para a Matemática, apesar de constarem para Língua Portuguesa e Literatura, Estudos Sociais (História e Geografia) e Fundamentos Biológicos, seguidas de diretrizes metodológicas relativos a essas disciplinas.

Além dessas diretrizes, Glacira está indicada, junto com Celestina Rosa e Silva, como tendo colaborado na elaboração das Diretrizes básicas para Direção da Aprendizagem em Matemática, publicado no Boletim referente aos anos de 1963-1964.

Glacira A. Barros e Celestina Rosa e Silva compuseram, ao menos entre os anos de 1963 e 1964, a "Divisão de Direção da Aprendizagem", tendo assinado as "Diretrizes para Direção da Aprendizagem em Matemática" (RIO GRANDE DO SUL, 1963-1964, p. 111-115). As diretrizes, voltadas ao "professorando", tratavam do planejamento em Matemática e remetem a diretrizes produzidas pelo Centro no ano de 1959, admitindo que se via naqueles anos uma valorização do papel da Matemática no Ensino Primário.

A influência piagetiana é explícita nessas diretrizes, pondo a explicação dos processos de aprendizagem das crianças nas "estruturas operatórias do pensamento". Defendem explicitamente ainda o uso do material Cuisenaire e do que chamaram de "material de Catherine Stern", associado. A influência de Piaget ou a referência 
ao uso desses materiais nos anos que se seguiram fizeram parte da formação matemática do Instituto de Educação Flores da Cunha (DA SILVA, DALCIN, 2019). No texto apresenta-se ainda uma proposta de conteúdo programático para formação de normalistas dividido em justificativa, objetivos, conteúdo programático, técnicas, material didático, avaliação, possibilidade de correlação, além dos livros consultados.

No mesmo Boletim, na "Bibliografia Direção da Aprendizagem em Matemática - 1963", "elaborada" apenas por Celestina Rosa e Silva, professora à disposição do CPOE, contendo cinquenta e duas indicações, está a referência de duas obras de "Stern: Discovering aritmetic, course I and II', obras diferentes da identificada no IE, Children Discover Arithmetic, da mesma autora (SILVA, 1963, p. 166) (grifo da autora).

Por fim, a técnica em Educação do CPOE, Odete Campos, elabora e assina um interessante documento para professores primários, "Fatos fundamentais das operações de números inteiros - Técnica de apresentação - Fixação da aprendizagem - Verificação", com o interesse de atender às "várias consultas de professôres de 1. $2 .^{\circ}$ e 3. ${ }^{\circ}$ anos, referentes ao ensino dos fatos básicos das operações de números inteiros [...]" (RIO GRANDE DO SUL, 1961-1962, p. 159), seguido de um item separado "Sugestões Práticas", contendo abordagem bastante diferente, propondo a construção de material e atividades de "fixação da aprendizagem", seguida de referências específicas. Contudo, é uma complementação ao item anterior apresentado como “Comunicado $n^{\circ} 7$ ". Ainda elaborado por ela aparece o "Comunicado $n^{\circ} 10 A$ " em que oferece esclarecimentos para os professores a respeito da "Conversão de Frações ao Mesmo Denominador" que, segundo consta no Boletim, tratava-se de uma demanda dos professores que haviam enviado ao CPOE "inúmeras consultas relativas a essa parte do 'PROGRAMA EXPERIMENTAL DE MATEMÁTICA' - edição de 1962" (RIO GRANDE DO SUL, 1961-1962, p. 181).

Uma caraterística interessante dos registros atribuídos a Odete é a indicação de bibliografias, contendo referências nacionais e internacionais. Dos quatro registros em que é possível identificar sua elaboração ou organização, um trata-se de uma bibliografia específica e no caso dos outros, sempre é possível acompanhar referências apoiando a explicação ou ao final. Tal marca é interessante e, de partida, já aponta para uma preocupação com a explicitação das referências, o que não é identificado como padrão fixo dos Boletins.

A partir desse levantamento apresentado, já foi possível identificar que diferentes secções e profissionais de distintos cargos, especialmente técnicas em educação e 
professoras à disposição do CPOE, produziram materiais relativos à Matemática, mas ainda não temos informações sobre como se estabeleceu a aproximação delas com a disciplina e os fundamentos teórico-metodológicos que compuseram suas produções, se teriam alguma formação mais específica ligada à área ou se em decorrência de demandas do trabalho que realizavam no Centro e, também, como passaram a assumir autoridade no que se refere a produzir orientações, relativas à Matemática, a serem cumpridas pelos professores primários do estado.

Avançar no conhecimento dos processos de definição, atribuição e distribuição de cargos no CPOE é particularmente interessante para nós, na medida em que nos possibilitará compreender melhor os interesses associados a essas personagens que assumiram função de experts no Ensino Primário e no Curso Normal no RS naqueles anos. Em outras palavras, é preciso reconhecer elementos que nos permitam caracterizá-las como detentoras de uma expertise, isto é, por meio das publicações que assinam, esteja atribuída a elas uma instância legítima, em que são distinguidas por seus conhecimentos atitudes ou experiências nas orientações a serem cumpridas pelos professores primários.

\section{Algumas considerações}

O que trouxemos até o momento identifica essas personagens com seus escritos nos Boletins e nos coloca muito mais perguntas sobre as trajetórias profissionais delas e de como acabaram por assumir certa autoridade no contexto educacional gaúcho naqueles anos, explicações que demandarão acesso a outro conjunto de fontes, como, por exemplo, outros documentos do CPOE que ainda não foi possível localizar.

Ao apresentarmos a atuação dessas mulheres, a partir de suas publicações, evidenciou-se a função de experts assumida por elas, ao lhes ser atribuída certa autoridade frente a toda uma categoria profissional no estado, tendo assumido, em função do lugar social que ocupavam como membros da equipe do CPOE, um papel de referência em relação ao ensino de Matemática para os professores primários e, por decorrência, certa influência na formação de normalistas. É inquestionável, tal como já mostrado em outras pesquisas relacionadas ao CPOE, aqui referidas, a importância que esse órgão teve na gestão do Ensino Primário e no Curso Normal, no período em que existiu. 
O grau de vinculação de cada uma dessas mulheres com a Matemática ainda é um tanto impreciso. No caso da professora Alda Cardoso Kremer, por exemplo, pelo o que consta nos Boletins, ela assinou documentos contendo orientações para o ensino de Matemática apenas no período em que esteve como diretora da Instituição. Já no caso das técnicas em educação, Eloah Brodt Ribeiro e Sarah Azambuja Rolla, que também foram diretoras da Instituição, assinaram documentos com orientações para o ensino de Matemática para além do período em que estiveram na gestão. Assinaram, inclusive, juntas, contando com a participação de Margarida Sirângelo, Noely Sagebin e Maria Fernandes Oliveira, "Sugestões para o ensino da Matemática nas classes de 1a ano”, publicado no Boletim de 1954/1955 e, após revisão, no Boletim de 1956/1957.

Enfim, o que apresentamos nesse texto é ainda a ponta de um novelo que exigirá outros tantos movimentos investigativos para melhor podermos explicar quem foram essas personagens identificadas que desempenharam a função de experts, no âmbito do Ensino Primário e no Curso Normal do Rio Grande do Sul naqueles anos, em particular quanto à associação delas com a Matemática. Sem dúvida, trata-se de contribuições que merecem mais algum esforço, uma vez que integram a construção histórica da identidade dos professores que ensinam Matemática no estado.

\section{Historical marks of the teacher who teaches Mathematics' identity: women on the spotlight in CPOE Bulletins}

\section{Abstract}

Seeking to offer a contribution to the historical construction of the teacher who teaches Mathematics' identity, we present an exercise of identification of characters who worked at the Educational Research and Orientation Center (CPOE), an organ of the Rio Grande do Sul Department of Education and Culture, a state in the south of Brazil. This is an attempt to better understand its operation in the management of Primary Education and, as a result, of the Normal School in the state. To this end, we adopt as sources the publications of the Center's Bulletins, dated from 1947 to 1966, related to the teaching of Mathematics, which are considered as representative of the CPOE official speeches in that period. As a result, it is highlighted that the authors of the material whose content was reflections, orientations and guidelines related to Mathematics were only women. Due to the place they occupied in the Center, women ended up assuming the role of experts, once their material was recognized as legitimate propositions of the Center for the teachers of the state.

Keywords: Elementary School ; Normal School ; Educational Research and Orientation Center ; Mathematics. Women. 


\section{Notas}

1 É o caso, por exemplo, de Peres (2000), Fischer (2005) e Quadros (2006).

2 Trata-se do projeto "Estudar para ensinar: práticas e saberes matemáticos nas escolas normais do Rio Grande do Sul (1889-1970)", desenvolvido por uma equipe de pesquisadores da Universidade Federal do Rio Grande do Sul, da Universidade Federal de Pelotas e da Universidade de Passo Fundo, todas do Rio Grande do Sul, com financiamento do CNPq (BÚRIGO, et al., 2016).

3 Referimo-nos a investigações com foco específico no sentido a que estamos nos propondo, embora reconheçamos diversas produções que tratam do CPOE, como, por exemplo, Peres (2000), Quadros (2006), Fischer e Fischer (2015), Fraga (2017), Sauter (2019), Sauter, Silva e Fischer (2019).

4 Já se encontram disponíveis no Repositório de Conteúdo Digital da UFSC doze desses Boletins: https:// repositorio.ufsc.br/handle/123456789/1769.

5 Como se pode localizar nos Boletins: (RIO GRANDE DO SUL, 1952-53, p. 2; 1958, p. 3-4; 1959, p. 47; 275; $281 ; 587 ; 1960$, p. $483-486 ; 1961-62$, p. $369 ; 472 ; 599)$.

\section{Referências}

BRASIL. Decreto-lei n. 8.530, de 2 de janeiro de 1946. Lei Orgânica do Ensino Normal. Rio de Janeiro: 1946. http://www.planalto.gov.br/ccivil_03/Decreto-Lei/1937-1946/Del8530.htm

BÚRIGO, Elisabete Z.; DALCIN, Andréia; SILVA, Circe Mary Silva da.; RIOS, Diogo F.; FISCHER, Maria Cecilia B.; PEREIRA, Luiz Henrique F. Estudar para Ensinar: práticas e saberes matemáticos nas escolas normais do Rio Grande do Sul (1889-1970). Projeto de Pesquisa. CNPq. Porto Alegre, 2016. $41 \mathrm{f}$.

DA SILVA, Sara Regina; DALCIN, Andréia. O Curso de Especialização em Didática da Matemática Moderna na Escola Primária no Instituto de Educação de Porto Alegre. Educação, v. 42, n. 2, p. 225-234, maio-ago. 2019. Disponível em: https://revistaseletronicas.pucrs.br/ojs/index. $\mathrm{php} /$ faced/article/view/33780

FISCHER, Beatriz Terezinha Daudt. Professoras: histórias e discursos de um passado presente. Pelotas: Seiva, 2005.

FISCHER, Beatriz Terezinha Daudt. Revista do Ensino/RS e Maria de Lourdes Gastal: duas histórias em conexão. História da Educação, ASPHE/FaE/UFPel, Pelotas, v. 14, n. 30, p. 61-79, jan./abr. 2010. https://seer.ufrgs.br/asphe/article/view/28911/0

FISCHER, Beatriz Terezinha Daudt; FISCHER, Maria Cecilia Bueno. Boletins do CPOE (19471966): recortes sobre o ensino da Matemática e a gestão dos processos avaliativos. Acta Scientiae, Canoas, v. 17, p. 76-93, 2015. http://www.periodicos.ulbra.br/index.php/acta/article/view/1457

FRAGA, Andreia Silva de. Trajetórias de alunas-mestras a professoras intelectuais da educação no Rio Grande do Sul (1920 a 1960). 2017. Tese (Doutorado em História). Pontifícia Universidade Católica do Rio Grande do Sul, Porto Alegre, 2017. http://tede2.pucrs.br/tede2/handle/tede/7670

HOFSTTETER; Rita; SCHNEUWLY, Bernard; FREYMOND, Mathilde de. Penetrar da verdade da escola para ter elementos concretos de sua avaliação - A irresistível institucionalização do expert em educação (século XIX e XX). In: HOFSTTETER, Rita; VALENTE, Wagner Rodrigues (Orgs.). Saberes em (trans)formação: tema central da formação de professores. São Paulo: Editora Livraria da Física, 2017, p. 55-112. 
KREMER, Alda Cardozo. Ofício Circular no 128 (Comunicado nํ2). In: RIO GRANDE DO SUL. Secretaria de Educação e Cultura. Centro de Pesquisas e Orientação Educacionais. Boletim do Centro de Pesquisas e Orientação Educacionais. Porto Alegre: SEC/CPOE, 1958, p. 27-28.

KREMER, Alda Cardozo. Ofício-circular nํ6․ In: RIO GRANDE DO SUL. Secretaria de Educação e Cultura. Centro de Pesquisas e Orientação Educacionais. Boletim do Centro de Pesquisas e Orientação Educacionais. Porto Alegre: SEC/CPOE, 1958, p. 284-290.

PERES, Eliane Teresinha. Aprendendo formas de pensar, de sentir e de agir: a escola como oficina da vida - discursos pedagógicos e práticas escolares da escola pública primária gaúcha. (1909 - 1959). 2000. Tese (Doutorado em Educação). Universidade Federal de Minas Gerais, Belo Horizonte, 2000. https://wp.ufpel.edu.br/hisales/files/2015/02/Tese-Eliane-Peres.pdf

PIMENTA, S. G. Formação de professores: Identidade e saberes da docência. In.: PIMENTA, S. G. (Org.). Saberes pedagógicos e atividade docente. São Paulo: Cortez, 1999, p. 15-34.

QUADROS, Claudemir. Reforma, ciência e profissionalização da educação: o Centro de Pesquisas e Orientação Educacionais do Rio Grande do Sul. Tese (Doutorado) - PPGEDU, UFRGS, 2006. https://lume.ufrgs.br/handle/10183/8911

RIBEIRO, Eloah Brodt. Considerações em tôrno do processo de medida adotado em Matemática para seleção dos candidatos à Escola de Professôres. In: RIO GRANDE DO SUL. Secretaria de Educação e Cultura. Centro de Pesquisas e Orientação Educacionais. Boletim do Centro de Pesquisas e Orientação Educacionais. Porto Alegre: SEC/CPOE, 1947, p. 13-30.

RIO GRANDE DO SUL. Secretaria de Educação e Cultura. Centro de Pesquisas e Orientação Educacionais. Boletim do Centro de Pesquisas e Orientação Educacionais. Porto Alegre: SEC/ CPOE, 1947. https://repositorio.ufsc.br/xmlui/handle/123456789/133652

RIO GRANDE DO SUL. Secretaria de Educação e Cultura. Centro de Pesquisas e Orientação Educacionais. Boletim do Centro de Pesquisas e Orientação Educacionais. Porto Alegre: SEC/ CPOE, 1952-1953. https://repositorio.ufsc.br/xmlui/handle/123456789/133996

RIO GRANDE DO SUL. Secretaria de Educação e Cultura. Centro de Pesquisas e Orientação Educacionais. Boletim do Centro de Pesquisas e Orientação Educacionais. Porto Alegre: SEC/ CPOE, 1954-1955. https://repositorio.ufsc.br/xmlui/handle/123456789/133651

RIO GRANDE DO SUL. Secretaria de Educação e Cultura. Centro de Pesquisas e Orientação Educacionais. Boletim do Centro de Pesquisas e Orientação Educacionais. Porto Alegre: SEC/ CPOE, 1956-1957. https://repositorio.ufsc.br/xmlui/handle/123456789/134148

RIO GRANDE DO SUL. Secretaria de Educação e Cultura. Centro de Pesquisas e Orientação Educacionais. Boletim do Centro de Pesquisas e Orientação Educacionais. Porto Alegre: SEC/ CPOE, 1958. https://repositorio.ufsc.br/xmlui/handle/123456789/134508

RIO GRANDE DO SUL. Secretaria de Educação e Cultura. Centro de Pesquisas e Orientação Educacionais. Boletim do Centro de Pesquisas e Orientação Educacionais. Porto Alegre: SEC/ CPOE, 1959. https://repositorio.ufsc.br/xmlui/handle/123456789/134574

RIO GRANDE DO SUL. Secretaria de Educação e Cultura. Centro de Pesquisas e Orientação Educacionais. Boletim do Centro de Pesquisas e Orientação Educacionais. Porto Alegre: SEC/ CPOE, 1960. https://repositorio.ufsc.br/xmlui/handle/123456789/135457 
RIO GRANDE DO SUL. Secretaria de Educação e Cultura. Centro de Pesquisas e Orientação Educacionais. Boletim do Centro de Pesquisas e Orientação Educacionais. Porto Alegre: SEC/ CPOE, 1961-1962. https://repositorio.ufsc.br/xmlui/handle/123456789/135180

RIO GRANDE DO SUL. Secretaria de Educação e Cultura. Centro de Pesquisas e Orientação Educacionais. Boletim do Centro de Pesquisas e Orientação Educacionais. Porto Alegre: SEC/ CPOE, 1963-1964. https://repositorio.ufsc.br/xmlui/handle/123456789/134507

RIO GRANDE DO SUL. Secretaria de Educação e Cultura. Centro de Pesquisas e Orientação Educacionais. Boletim do Centro de Pesquisas e Orientação Educacionais. Porto Alegre: SEC/ CPOE, 1965-66. https://repositorio.ufsc.br/xmlui/handle/123456789/134573

RIOS, Diogo Franco; FISCHER, Maria Cecilia Bueno. "Especialmente dedicada aos futuros espaçonautas": discursos modernizadores nos artigos da Campanha de Matemática da Revista do Ensino/RS (1961). Revista Diálogo Educacional, Curitiba, v. 16, n. 49, p. 589-610, jul./set. 2016. https://periodicos.pucpr.br/index.php/dialogoeducacional/article/view/4939

RIOS, Diogo Franco; FISCHER, Maria Cecilia Bueno. Estratégias de Renovação Pedagógica: a atuação da Comissão de Estudo do Livro e do Material Didático do CPOE/RS na escolha dos livros didáticos de matemática nos anos 1960. Revista de Investigação e Divulgação em Educação Matemática, Juiz de Fora, v. 2, n. 1, p. 53-70, jan./jul. 2018. https://periodicos.ufjf.br/index.php/ ridema/article/view/27363

RIOS, Diogo Franco; FISCHER, Maria Cecilia Bueno. Memórias de uma Normalista: entrevista com Beatriz Daudt Fischer. Educação, Porto Alegre, v. 42 n. 2, p. 264-275, maio-ago. 2019. https:// doi.org/10.15448/1981-2582.2019.2.33785

ROLLA, Sarah Azambuja; RIBEIRO, Eloah Brodt; SIRÂNGELO, Margarida; SAGEBIN, Noely; OLIVEIRA, Maria Fernandes. Sugestões para o Ensino de Matemática nas Classes de I Ano. In: RIO GRANDE DO SUL. Secretaria de Educação e Cultura. Centro de Pesquisas e Orientação Educacionais. Boletim do Centro de Pesquisas e Orientação Educacionais. Porto Alegre: SEC/ CPOE, 1954-1955, p. 123-135.

ROLLA, Sarah Azambuja; RIBEIRO, Eloah Brodt; SIRÂNGELO, Margarida; SAGEBIN, Noely; OLIVEIRA, Maria Fernandes. Relativo ao Ensino da Matemática (Revisado). In: RIO GRANDE DO SUL. Secretaria de Educação e Cultura. Centro de Pesquisas e Orientação Educacionais. Boletim do Centro de Pesquisas e Orientação Educacionais. Porto Alegre: SEC/CPOE, 1956-1957, p. 88-97.

SAUTER, Leonardo Thomaz. Saberes matemáticos a ensinar nos boletins do Centro de Pesquisas e Orientação Educacionais/RS (1947-1966). In: XXIII Encontro Brasileiro de Estudantes de Pós-Graduação em Educação Matemática, 2019, São Paulo. Anais... São Paulo: Cruzeiro do Sul, 2019. v. 23. p. 1-10. http://eventos.sbem.com.br/index.php/EBRAPEM/EBRAPEM2019/paper/ viewFile/713/583

SAUTER, Leonardo Thomaz; SILVA, Daniela Thiemy Sada; FISCHER, Maria Cecilia Bueno. Publicações para as escolas normais presentes nos boletins do Centro de Pesquisas e Orientação Educacionais do RS. In: $2^{\circ}$ Seminário Práticas e Saberes Matemáticos nas Escolas Normais do Rio Grande do Sul, 2019, Pelotas. Anais... Porto Alegre: Universidade Federal do Rio Grande do Sul, 2019. v. 2. p. 62-85. http://www.ufrgs.br/escolasnormais/seminario-2/anais_2_escolasnormais.pdf

SILVA, Celestina Rosa e. Bibliografia Direção da Aprendizagem em Matemática - 1963 -. In: RIO GRANDE DO SUL. Secretaria de Educação e Cultura. Centro de Pesquisas e Orientação Educacionais. Boletim do Centro de Pesquisas e Orientação Educacionais. Porto Alegre: SEC/ CPOE, 1963-1964, p. 165-166. 
TAMBARA, E. Profissionalização, escola normal e feminilização: magistério sul-rio-grandense de instrução pública no século XIX. História da Educação. Pelotas: ASPHE /FaE/UFPel, n.3, p.35-58, abr.1998. https://seer.ufrgs.br/asphe/article/view/30720

VALENTE, Wagner Rodrigues (Org.). Educadoras Matemáticas: memórias, docência e profissão. São Paulo: Editora Livraria da Física, 2013.

VALENTE, Wagner Rodrigues; ALMEIDA, André Francisco de; SILVA, Marylúcia Cavalcante. Saberes em (Trans)formação e o Papel dos Experts: currículos, ensino de matemática e formação de professores, 1920-2020. Acta Scientiae. v. 22 n. 5, p. 65-83, set./out. 2020. http://www.periodicos. ulbra.br/index.php/acta/article/view/6004/pdf_1

WERLE, Flávia Obino Corrêa. Práticas de gestão e feminização do magistério. Cadernos de Pesquisa, São Paulo, v. 35, n. 126, p. 609-634, set./dez. 2005. https://www.scielo.br/scielo.php?pi$\mathrm{d}=$ S0100-15742005000300005\&script=sci_abstract\&tlng=pt 